Davies, A. G., DOMINY, N. J., Peters, A. D., et al (1995) HIV in injecting drug users in Edinburgh: prevalence and correlates. Journal of AIDS and Human Retrovirology. 8, 399-405.

GRIFFIN, S., PETERS, A. \& REID, M. (1993) Drug misusers in Lothian. Changes in injecting habits 1988-90. British Medical Journal, s06, 693.

J. GreenwoOd, Community Drug Problem Service, Royal Edinburgh Hospital, 40 Colinton Road, Edinburgh EH10 5BT

\section{Service contact prior to suicide}

Sir: We were interested to read Meats \& Solomka's perspective on suicide in Central Nottinghamshire from 1987-1991 (Psychiatric Bulletin, 19, 666-669) and their points regarding consulting behaviour and potential for intervention.

We conducted a survey of Nottingham suicides during 1994. Data were collected from Coroner's records, hospital database and a postal questionnaire $(75 \%$ returned) from general practitioners (GP) who encountered suicides, or open and misadventure verdicts judged as suicides. Fifty-seven deaths by suicide were identified (7.8 per 100000 pop.), $75 \%$ male, and $54 \%$ men under 35 years.

We wish to make two points. Firstly, a considerable number of Meats \& Solomka's "nonconsulters" (i.e. no primary or secondary service contact in 12 months prior to death) may have attended casualty or non-psychiatric medical services within this time. In our sample $37 \%$ of cases had attended casualty (often with deliberate self-harm), and $32 \%$ other medical services, and for seven cases casualty was their only contact. These casualty attenders in particular represent a significant group since they are at known risk of death within one year of DSH and suggest potential for targetable intervention in a readily identifiable group. This compares with identification of potential suicides within primary care, a comparattvely rare event estimated as one in 51199 GP consultations (MacDonald, 1992).

Secondly, although GP consultations by potential suicide cases increased before death and provided an "opportunity to be recognised", in our study the issue of suicide was not raised with over half of cases despite recognition of psychological distress in $67 \%$ cases and prior DSH in $29 \%$. Indeed, only one of 43 GPs thought their particular suicide cases preventable, suggesting an overall reluctance by GPs to see suicide prevention as practically relevant to them.

MACDONALD, A. (1992) Suictde prevention by GPs? British Journal of Psychiatry, 161, 574.

J. Milton AND B. Ferguson, East \& Carlton Mental Health Team, Stonebridge Centre, Carlton Road, Nottingham NG3 2FH

\section{Distinction awards}

Sir: Dr Hyde (Psychiatric Bulletin, 20, 117) reports that consultants who change posts may be inadequately considered for $\mathrm{C}$ distinction awards (now 'discretionary points') because their achievements in a previous position are not known.

There is another hazard that also applies to higher awards. Distinction awards are based on merit not seniority but award committees are favourably influenced by the duration of consultant responsibility. In the case of consultants who change posts their date of achieving consultant status is sometimes recorded for award committees as the date of last appointment. The error of course shortens by some years the true period of consultantship.

Consultants who change jobs would be wise to ensure that their new Regional Health Authority and the Secretariat of the Advisory Committee on Distinction Awards register for this purpose the first date of consultant appointment.

J. S. MADDEN, 87 Mill Lane, Upton-by-Chester, Chester CH2 $1 \mathrm{BS}$

\section{The rise and fall of anti-psychiatry}

Sir: Nasser (Psychiatric Bulletin, 19, 743-746) makes some interesting points, several of which merit comment. Cooper defines "anti-psychiatry" quite specifically in Psychiatry and Anti-Psychiatry (1970), a text cited by Nasser. Cooper's aim appears to have been to coin a term which specifies a practice which is the converse of orthodox practice. His use of the term is clear:

"A more profound questioning has led some of us to propose conceptions and procedures that seem quite antithetic to the conventional ones - in fact what may be regarded as a germinal ant1psychiatry."

Commentators have often misunderstood the term as simply one more way of expressing antagonism to orthodox psychiatric practice rather than an antithesis. This mistaken use of the term loses the subtlety of the original, and is often misapplied to a heterogeneous collection of views, many of which would have found approval with Cooper or Laing.

Laing and anti-psychiatry are taken to be synonymous by some authors but he appears not to promote the term in his writings, to have neither made a contribution to, nor offered an endorsement of Laing and Anti-Psychiatry (1971) and in Wisdom, Madness and Folly (1985) wrote

"I have never called myself an anti-psychiatrist, and have disclaimed the term from when first my friend and colleague, David Cooper, introduced it". 